University of Nebraska - Lincoln

DigitalCommons@University of Nebraska - Lincoln

U.S. Department of Veterans Affairs Staff

Publications

U.S. Department of Veterans Affairs

2008

Solar Ultraviolet B Radiation Compared with Prostate Cancer

Incidence and Mortality Rates in United States

Janet L. Colli

University of Alabama - Birmingham, jan.colli@ccc.uab.edu

William B. Grant

Veterans Affairs Medical Center

Follow this and additional works at: https://digitalcommons.unl.edu/veterans

Colli, Janet L. and Grant, William B., "Solar Ultraviolet B Radiation Compared with Prostate Cancer Incidence and Mortality Rates in United States" (2008). U.S. Department of Veterans Affairs Staff Publications. 32.

https://digitalcommons.unl.edu/veterans/32

This Article is brought to you for free and open access by the U.S. Department of Veterans Affairs at DigitalCommons@University of Nebraska - Lincoln. It has been accepted for inclusion in U.S. Department of Veterans Affairs Staff Publications by an authorized administrator of DigitalCommons@University of Nebraska - Lincoln. 


\title{
Solar Ultraviolet B Radiation Compared with Prostate Cancer Incidence and Mortality Rates in United States
}

\author{
Janet L. Colli, and William B. Grant
}

OBJECTIVE

To investigate whether the prostate cancer incidence and mortality rates in the United States correlate inversely with solar ultraviolet (UV) B radiation levels computed from a mathematical model using forecasted ozone levels, cloud levels, and elevation. Another objective was to explore whether the annual prostate cancer rates correlated more strongly with the cumulative UVB exposure for the year or for exposure during certain seasons.

METHODS

The age-adjusted incidence and mortality cancer rates for black and white men in the continental United States were correlated with the mean UV index values averaged for the year and for each season.

RESULTS

We found an inverse correlation between the UVB levels and prostate cancer incidence $(R=-0.42$, $P<0.01)$ and mortality rates $(R=-0.53, P<0.001)$ for white men and for incidence $(R=-0.40$, $P<0.05)$ for black men, but the strength of the correlation depended on the season of UVB irradiance. No statistically significant results for black male mortality were found. The annual prostate cancer incidence and mortality rates for white men correlated most strongly with UVB exposure levels in the fall and winter, and incidence rates for black men correlated with UVB exposure levels in the summer.

CONCLUSIONS Increased solar UVB radiation might reduce the risk of prostate cancer, but the efficacy depends on the season of UVB irradiance. UROLOGY 71: 531-535, 2008. (C) 2008 Elsevier Inc.

$\mathrm{I}$ nadequate solar ultraviolet (UV) B irradiance has been implicated as a risk factor for prostate cancer incidence and mortality. ${ }^{1-7}$ A number of recent studies have found that the survival of patients with breast, colon, and prostate cancer depends on the season of diagnosis, and sunlight exposure has been suggested as the cause. ${ }^{8-10}$

An association between the circulating serum 25 hydroxyvitamin D [25(OH)D] (calcidiol) and a reduced risk of prostate cancer has been suggested. ${ }^{11}$ Vitamin $D$ is obtained by humans from exposure to sunlight or ingestion of vitamin D. ${ }^{12}$ The hormonal form of vitamin D, 1,25-dihydroxyvitamin $\mathrm{D}_{3}$ (calcitriol) has been identified as a potent antiproliferative and pro-differentiation hormone. ${ }^{13}$ A recent report on the epidemiology of vitamin $\mathrm{D}$ and cancer incidence and mortality has provided a thorough review of the published data on this subject. ${ }^{14}$

Most humans depend on sunlight exposure to satisfy their requirements for vitamin D. Solar UVB radiation is

From the Department of Urology, University of Alabama, Birmingham, School of Medicine; Veterans Affairs Medical Center, Birmingham, Birmingham, Alabama; and Sunlight, Nutrition and Health Research Center (SUNARC), San Francisco, Califormia

Reprint requests: Janet L. Colli, M.D., Division of Urology, Department of Urology, University of Alabama, Birmingham, School of Medicine, FOT 1105, 1530 Third

Avenue South, Birmingham, AL 35294. E-mail: jan.colli@ccc.uab.edu

Submitted: June 27, 2007, accepted (with revisions): October 25, 2007 absorbed by 7-dehydrocholesterol in the skin, leading to its transformation to previtamin $\mathrm{D}_{3}$, which is rapidly converted to vitamin $\mathrm{D}_{3}$. The production of vitamin $\mathrm{D}_{3}$ in the skin is affected by the season, latitude, time of day, and skin pigmentation. ${ }^{15}$

The plan of this study was to determine whether the prostate cancer risks in the United States correlate inversely with UV index values that were developed by the National Oceanic and Atmospheric Administration (NOAA) in collaboration with the Environmental Protection Agency (EPA). ${ }^{16}$ The UV index is a forecast of the amount of UV radiation expected to reach the earth's surface, weighted by the McKinlay-Diffey erythema action spectrum to reflect the human skin's response. The UV index value is not only a more precise forecast of UVB exposure associated with the production of vitamin $\mathrm{D}_{3}$ than that used in past studies, but its application allows for a probe of the relationship between annual cancer rates and UVB radiation exposure levels for the year and for different periods during the year.

Because UV radiation levels vary significantly throughout the year, we compared the cancer rates to the UV index values averaged for the entire year, as well as those for each season. The objective was to explore whether the strength of any correlations found depended on the total annual UVB exposure or the season in which the exposure oc- 
Table 1. Summary statistics for cancer incidence and mortality rates for states in United States

\begin{tabular}{lccccc}
\hline & & & & \multicolumn{2}{c}{ Percentile } \\
\cline { 4 - 5 } Prostate Cancer & States $(\mathrm{n})$ & Mean & Minimum & Maximum & 25th \\
\hline $\begin{array}{l}\text { Incidence } \\
\text { White men }\end{array}$ & $43^{*}$ & 143.6 & 116.1 & 186.0 & 131.9 \\
$\begin{array}{l}\text { Black men } \\
\text { Mortality }\end{array}$ & $35^{\dagger}$ & 211.1 & 115.5 & 276.1 & 193.0 \\
$\quad$ White men & 48 & 32.8 & 27.7 & 39.0 & 231.0 \\
$\quad$ Black men & $33^{\dagger}$ & 73.6 & 53.0 & 87.3 & 31.6 \\
\hline
\end{tabular}

Cancer incidence rates for 2003 to 2004 and mortality rates for deaths from 1992 to 2001.

* Arizona, Mississippi, Tennessee, Virginia, and Wyoming (group 1) not included.

† Group 1 plus Idaho, Maine, Montana, New Hampshire, North Dakota, South Dakota, Utah, and Vermont not included.

‡ Idaho, lowa, Maine, Minnesota, Montana, Nebraska, New Hampshire, New Mexico, North Dakota, Oregon, Rhode Island, South Dakota, Utah, Vermont, and Wyoming not included.

Table 2. UV index* values averaged for year and seasons for 48 states across United States

\begin{tabular}{lccccc}
\hline & & & & \multicolumn{2}{c}{ Percentile } \\
\cline { 3 - 5 } Season & Mean & Minimum & Maximum & 25th & 75th \\
\hline Annual & 4.3 & 2.7 & 6.4 & 5.5 & 1.0 \\
Winter & 1.6 & 0.6 & 3.8 & 4.0 & 2.1 \\
Spring & 4.9 & 3.2 & 7.7 & 6.4 & 5.8 \\
Summer & 7.3 & 5.1 & 5.6 & 2.6 & 8.5 \\
Fall & 3.4 & 1.9 & 5.5 & 4.2 \\
\hline
\end{tabular}

UV, ultraviolet.

UV index values are averaged from 1995 to 2001.

* UV index is erythema dose calculated from forecasted amount of ultraviolet radiation expected to reach the Earth's surface at time when the Sun is highest in the sky.

curred. The results could reveal whether cancer rates correlate more strongly with UVB levels in the winter when reduced vitamin $D_{3}$ synthesis occurs or UVB levels in the summer when high levels of vitamin $D_{3}$ synthesis result in accumulation of vitamin $\mathrm{D}$ in body fat that becomes available for release into the circulating blood at a later time. In winter, most humans are unable to synthesize vitamin $D$ from solar UVB radiation in many areas of most of the United States. ${ }^{17}$ Because the pigmentation in the skin of blacks inhibits the formation of vitamin $D_{3}$ from UVB radiation, ${ }^{18}$ the cancer rates for blacks and whites were compared with UV indexes separately.

\section{MATERIAL AND METHODS}

\section{Data Sources}

The prostate cancer incidence rates for the states in the continental United States for 2000 to 2001 were obtained from the State Cancer Registry and the National Program of Cancer Registries Cancer Surveillance. ${ }^{19}$ The summary statistics are presented in Table 1. The incidence data for some states were not included in the database because the data quality standards were not met and the data had not been published. The incidence rates were age adjusted to the 2000 U.S. standard population.

The cancer mortality rates for states in the continental United States were obtained from the Surveillance, Epidemiology, and End Results program of the National Cancer Institute. ${ }^{20}$ The cancer mortality rates covered the deaths (all ages) from 1992 to 2001 and were age adjusted to a standard population (2000 U.S. population). The states with 15 or fewer deaths during the period studied were not included.
The UV index values were obtained from the NOAA, which developed these data in collaboration with the EPA. ${ }^{16}$ The NOAA/EPA UV index is computed from a mathematical model using the forecasted ozone levels, cloud levels, and elevation. The model is used to determine the UV irradiance from 290 to $400 \mathrm{~nm}$. The irradiance is weighted by the McKinlayDiffey erythema action spectrum, resulting in a peak value near $308 \mathrm{~nm}$, with a strong weighting for the UVB range (approximately 290 to $320 \mathrm{~nm}$ ). ${ }^{13}$ During solar UV irradiance, photons in the UVB range are absorbed by the cutaneous 7-dehydrocholesterol to form previtamin $\mathrm{D}_{3} .{ }^{21}$

The NOAA/EPA UV index values for 48 states were obtained from 1995 to 2001 and averaged to dampen any variations that might have occurred from data for a single year. The UV index values averaged for the year and for each season are presented in Table 2. Examination of the raw data not shown suggested that UV levels across the country are asymmetric because of differences in surface elevation and stratospheric ozone levels. The Rocky Mountain states have greater UV levels (especially in the summer) than states in the Midwest or east. The peak UV index value exceeded 9 for Utah, Colorado, and Nevada in the summer but was approximately 7 for Illinois, Ohio, and Virginia, which are at about the same latitude. The differences in the UV indexes between the east and west were less pronounced along the $30^{\circ}$ and $40^{\circ}$ latitude, although the tendency was similar.

\section{Statistical Analysis}

Initially, the data for the cancer incidence and mortality rates and UV indexes were examined for normalcy and to identify outliers. All variables appeared to possess a normal, or near normal, distribution, and no outliers were found in the data set. 
Table 3. Correlation coefficients between prostate cancer rates and mean UV indexes* for states in United States

\begin{tabular}{|c|c|c|c|c|}
\hline \multirow[b]{2}{*}{ UV Index } & \multicolumn{2}{|c|}{ PCa Incidence } & \multicolumn{2}{|c|}{ PCa Mortality } \\
\hline & Whites & Blacks & Whites & Blacks \\
\hline Annual & $-0.36^{\dagger}$ & $-0.30^{\ddagger}$ & $-0.46^{\S}$ & $0.15^{\dagger}$ \\
\hline Winter & $-0.42^{\S}$ & $-0.20^{\ddagger}$ & $-0.53^{\pi}$ & $0.24^{\ddagger}$ \\
\hline Spring & $-0.38^{3}$ & $-0.27^{\ddagger}$ & $-0.48^{\S}$ & $0.18^{\dagger}$ \\
\hline Summer & $-0.23^{\dagger}$ & $-0.40^{3}$ & $-0.31^{\S}$ & $0.03^{\dagger}$ \\
\hline Fall & $-0.40^{\S}$ & $-0.26^{\ddagger}$ & $-0.50^{\pi}$ & $0.18^{\neq}$ \\
\hline
\end{tabular}

UV, ultraviolet; $P C a$, prostate cancer.

Annual and seasonal mean UV indexes averaged from 1995 to 2001; cancer incidence rates for 2003 or 2004; mortality rates for deaths from 1992 to 2001.

* UV index is erythema dose calculated from forecasted amount of UV radiation expected to reach earth's surface when sun is highest in sky.

$+P<0.05$, two-tailed.

${ }^{\dagger} P>0.05$, two-tailed.

\& $P<0.010$, two-tailed.

I $P<0.001$, two-tailed.

Outliers were defined as values outside two standard deviations from the mean.

The cancer rates for the states were correlated with the UV index values for the year and for each season. Simple regression coefficients (B), correlation coefficients $(R)$ and $P$ values (two sided) were calculated to examine the association between cancer rates and monthly UV indexes in those cases with the strongest correlation. The statistical analyses in this study were performed using the software program Statistical Package for Social Sciences for Windows, version 12.0 (SPSS, Chicago, Ill).

\section{RESULTS}

The correlation coefficients between the mean UV index values and prostate cancer rates are presented in Table 3. The maximal correlation coefficient for incidence was $R=-0.42(P<0.01)$ for white men and $R=-0.40(P<0.05)$ for black men. The maximal correlation coefficient for mortality for white men was $R=-0.53(P<0.001)$. No statistically significant results for black male mortality were found.

The prostate cancer incidence and mortality rates for white men correlated most strongly with the UV indexes in the fall and winter/spring, and the prostate cancer incidence for black men correlated most strongly with the UV index in the summer. Not only was the correlation coefficient greater in the peak season, but the $P$ value was smaller, suggesting a lower probability that the results were false.

Simple regression coefficients were calculated to examine the association between cancer rates and monthly UV indexes in cases in which the correlation was close. The regression coefficient for the season with the strongest correlation was $B=-9.9$ (95\% confidence interval -16.7 to -3.2$)$ for the incidence for white men (winter), $\mathrm{B}=-12.1$ (95\% confidence interval -22.0 to -2.2$)$ for the incidence for black men (summer), and $\mathrm{B}=-1.6$ ( $95 \%$ confidence interval -2.4 to -0.9 ) for mortality for white men (winter). Outliers in the model outputs included the incidence for white men in Kentucky (116.1 actual, 144.0 calculated), the incidence for black men in West Virginia (158.5 actual, 213.9 calculated), and mortality for white men in Wyoming (39.0 actual, 32.8 calculated). The regression coefficient for the mortality rates for black men was 0.2 (95\% confidence interval -2.4 to $2.8 ; P=0.88)$.

\section{COMMENT}

The correlation between prostate cancer rates and UV indexes for white men was strongest in the fall and winter, moderate in the spring, and weak or nonexistent in the summer. These findings suggest that vitamin D synthesis from sunlight in the spring and summer might be sufficient to afford protection from prostate cancer for white men in most of the United States, but that the risk is increased from the modest amounts synthesized throughout the rest of the year.

However, prostate cancer mortality rates have a different geographic distribution in the United States than many of the other vitamin D-sensitive cancers. The rates are high in the northwest and northeast, in contrast to other cancers in which the rates are intermediate in the northwest. Prostate cancer was the only vitamin D-sensitive cancer that had a significant correlation with latitude but not to the index of July 1992 UVB doses used in the study by Grant and Garland. ${ }^{22}$ Latitude can be interpreted as an index of wintertime UVB related to the solar zenith angle rather than the very pronounced asymmetry in the summertime UVB in the United States that results from differences in surface elevation and stratospheric ozone between the eastern and western states. A more recent study found that several other cancers, including bladder, ovarian, prostate, testicular, and Hodgkin's and non-Hodgkin's lymphoma, also had a correlation with latitude on multiple linear regression analysis that included the summertime UVB. Viral infections have been reported as risk factors for these cancers. A paper ${ }^{23}$ has been submitted suggesting that the correlation with wintertime solar UVB results from the effect of vitamin D reducing the risk of viral respiratory diseases in the summer. ${ }^{24}$

In contrast to the prostate cancer results for white men, the prostate cancer incidence for black men exhibited a statistically significant correlation with the UVB radiation levels only in the summer. Vitamin D synthesis, which is low in the winter for whites in most of the United States, ${ }^{17}$ is undoubtedly lower for blacks. Black men, with increased skin melanin pigmentation, might not be able to synthesize sufficient vitamin D from ambient UVB radiation exposure in seasons other than summer to affect prostate cancer progression. An increase in skin melanin pigmentation will absorb solar ultraviolet radiation and significantly reduce the production of vitamin $D_{3}$ in the skin. ${ }^{25}$ Studies of black men and Mexican Americans have suggested that they have lower circulating concentrations of calcidiol. ${ }^{26}$ The circulating concentration of calcidiol is reported to reflect the cu- 
mulative effects of exposure to sunlight and dietary intake of vitamin D. ${ }^{12}$

Although the UV indexes correlated with the incidence of prostate cancer for black men, no correlation was found with mortality for black men. These results are consistent with those of another recent study. ${ }^{27}$ It is possible that black men cannot synthesize sufficient vitamin D from ambient UVB radiation exposure to affect disease progression after its initiation. Some studies, ${ }^{28-30}$ although not all, ${ }^{31}$ have suggested that black men have a more advanced form of prostate cancer at diagnosis, which might reduce the benefits of the lower levels of vitamin $\mathrm{D}$ that blacks are able to synthesize from exposure to sunlight. This would support our finding that UVB exposure benefits the incidence but not mortality for black men. The results in the study by Grant ${ }^{27}$ were determined from mortality data for 1970 to 1994 in contrast to the data in the present study which were determined from mortality data for 1992 to 2001. Concern has been increasing about the risk of skin cancer from solar UV irradiance starting in the early 1980s, and indications exist that this has led to changes in the geographic variation of cancer mortality rates in the United States. Although black Americans are at a much lower risk of skin cancer than are white Americans, the skin cancer prevention messages generally do not make that clear; thus, black Americans could be avoiding solar UVB irradiance as well.

Our results seem to suggest that a critical sunlight threshold exists below which the risk of prostate cancer increases. This critical threshold is lower for white men than for black men. For white men, this threshold is exceeded in the whole country in the summer but is not met in the northern part of the country in the other seasons. This critical threshold value for white men is approximately 5.1 -the minimal UV index value for the summer from Table 2. For black men, this threshold is only exceeded in the summer in the south. This threshold value is about 8.1 - the mean UV index value for the states of the Southeast in the summer. Hence, the seasons other than summer are most relevant for white men, and the summer is the most relevant for black men.

The uncertainties in this study stemmed from a number of factors. The number of data points (especially for cancer incidence) used in this study were not large. The UV data were taken at one, or several, points within a state, and variations throughout the state were not taken into consideration. Also, the UV data were aggregated, and what might apply on a population basis might not necessarily be observed on an individual basis. This study assessed total mortality as opposed to case fatality. Also, aggregating the data by state did not allow for consideration of relationships within a state and limited the control of confounders and effects modifiers. This study had a number of potential biases, and the use of the UV index as a surrogate for UV exposure has a high degree of uncertainty. For example, varying lifestyles across the
United States could result in differences in exposure to solar UVB (eg, people in the west might tend to spend more time outdoors than people in the northeast); the amount of time that people spend outdoors varies depending on their lifestyle or occupation; difference in clothing styles will affect the amount of UVB radiation reaching the skin; and pigmentation varies among whites with different skin types.

\section{CONCLUSIONS}

Increased solar UVB irradiance might reduce the risk of prostate cancer but the efficacy could depend on the season of UVB irradiance. Both the incidence and mortality of prostate cancer for white men correlated most strongly with the UVB levels in the fall, winter, and spring. The prostate cancer incidence for black men correlated most strongly with the UVB levels in the summer.

\section{References}

1. Hanchette CL, and Schwartz GG: Geographic patterns of cancer mortality. Cancer 70: 2861-2869, 1992.

2. Grant WB: Geographic variation of prostate cancer mortality rates in the United States: implications for prostate cancer risk related to vitamin D. Int J Cancer 111: 470-471, 2004.

3. Schwartz GG: Vitamin D and the epidemiology of prostate cancer. Semin Dial 18: 276-289, 2005.

4. Schwartz GG, and Hanchette CL: UV, latitude, and spatial trends in prostate cancer mortality: all sunlight is not the same (United States). Cancer Causes Control 17: 1091-1101, 2006.

5. Boscoe FP, and Schymura MJ: Solar ultraviolet-B exposure and cancer incidence and mortality in the United States, 1993-2002. BMC Cancer 6: 264-268, 2006.

6. John EM, Koo J, and Schwartz GG: Sun exposure and prostate cancer risk: evidence for a protective effect of early-life exposure. Cancer Epidemiol Biomarkers Prev 16: 1283-1286, 2007.

7. Rukin NJ, Zeegers MP, Ramachandran S, et al: A comparison of sunlight exposure in men with prostate cancer and basal cell carcinoma. Br J Cancer 96: 523-528, 2007.

8. Robsahm TE, Tretli S, Dahlback A, et al: Vitamin $\mathrm{D}_{3}$ from sunlight may improve the prognosis of breast-, colon- and prostate cancer (Norway). Cancer Causes Control 15: 149-158, 2004.

9. Lim HS, Roychoudhuri R, Peto J, et al: Cancer survival is dependent on season of diagnosis and sunlight exposure. Int J Cancer 119: 1530-1536, 2006.

10. Lagunova Z, Porojnicu AC, Dahlback A, et al: Prostate cancer survival is dependent on season of diagnosis. Prostate 67: 13621370, 2007.

11. Corder EH, Guess HA, Hulka BS, et al: Vitamin D and prostate cancer: a prediagnostic study with stored sera. Cancer Epidemiol Biomarkers Prev 2: 467-472, 1993.

12. Vitamin D, in Standing Committee on the Scientific Evaluation of Dietary Reference Intakes, Food and Nutrition Board, Institute of Medicine: Dietary Reference Intakes for Calcium, Phosphorus, Magnesium, Vitamin D, and Fluoride. National Academy of Sciences, National Academy Press, 1997, 250-287.

13. Moreno J, Krishnan AV, Swami S, et al: Regulation of prostaglandin metabolism by calcitriol attenuates growth stimulation in prostate cancer cells. Cancer Res 65: 7917-7925, 2005.

14. Giovannucci E: The epidemiology of vitamin D and cancer incidence and mortality: a review (United States). Cancer Causes Control 16: 83-95, 2005. 
15. Holick MF: Sunlight and vitamin D for bone health and prevention of autoimmune diseases, cancers, and cardiovascular disease. Am J Clin Nutr 80(6 suppl): 1678S-1688S, 2004.

16. National Oceanic and Atmospheric Administration (NOAA)/U. S. Environmental Protection Agency (EPA) UV Index. Available from: www.cpc.ncep.noaa.gov/products/stratosphere/uv_index/. Accessed at January 6, 2005.

17. Webb AR, Kline L, and Holick MF: Influence of season and latitude on the cutaneous synthesis of vitamin $\mathrm{D}_{3}$ : exposure to winter sunlight in Boston and Edmonton will not promote vitamin $\mathrm{D}_{3}$ synthesis in human skin. J Clin Endocrinol Metab 67: 373-378, 1988.

18. Clemens TL, Adams JS, Henderson SL, et al: Increased skin pigment reduces the capacity of skin to synthesise vitamin $\mathrm{D}_{3}$. Lancet 1: 74-76, 1982.

19. State Cancer Profiles. Available from http://statecancerprofiles.cancer. gov. Accessed September 10, 2007.

20. Surveillance, Epidemiology, and End Results (SEER) program (www. seer.cancer.gov). SEER*Stat Database: Mortality—All COD, PublicUse with State, Total U.S. (1969-2001), National Cancer Institute, DCCPS, Surveillance Research Program, Cancer Statistics Branch, released April 2004. Underlying mortality data provided by NCHS. Available from www.cdc.gov/nchs. Accessed January 4, 2005

21. MacLaughlin JA, Anderson RR, and Holick MF: Spectral character of sunlight modulates photosynthesis of previtamin $\mathrm{D}_{3}$ and its photoisomers in human skin. Science 216: 1001-1003, 1982.

22. Grant WB, and Garland CF: The association of solar ultraviolet $B$ (UVB) with reducing risk of cancer: multifactorial ecologic analysis of geographic variation in age-adjusted cancer mortality rates. Anticancer Res 26: 2687-2699, 2006.
23. Grant WB. Hypothesis-ultraviolet-B irradiance and vitamin D reduce the risk of viral infections and thus their sequelae, including autoimmune diseases and some cancers. Photochem Photobiol. In press.

24. Cannell JJ, Vieth R, Umhau JC, et al: Epidemic influenza and vitamin D. Epidemiol Infect 134: 1129-1140, 2006.

25. Clemens TL, Adams JS, Henderson SL, et al: Increased skin pigment reduces the capacity of skin to synthesise vitamin $D_{3}$. Lancet 1: 74-76, 1982.

26. Zadshir A, Tareen N, Pan D, et al: The prevalence of hypovitaminosis D among US adults: data from the NHANES III. Ethn Dis 15(4 suppl 5): S5-97-S5-101, 2005.

27. Grant WB: Lower vitamin-D production from solar ultraviolet-B irradiance may explain some differences in cancer survival rates. J Natl Med Assoc 98: 357-364, 2006.

28. Oakley-Girvan I, Kolonel LN, Gallagher RP, et al: Stage at diagnosis and survival in a multiethnic cohort of prostate cancer patients. Am J Public Health 93: 1753-1759, 2003.

29. Fowler JE Jr, Bigler SA, and Farabaugh PB: Prospective study of cancer detection in black and white men with normal digital rectal examination but prostate specific antigen equal or greater than 4.0 ng/mL. Cancer 94: 1661-1667, 2002.

30. Schwartz KL, Crossley-May H, Vigneau FD, et al: Race, socioeconomic status and stage at diagnosis for five common malignancies. Cancer Causes Control 14: 761-766, 2003.

31. Kang JS, Maygarden SJ, Mohler JL, et al: Comparison of clinical and pathological features in African-American and Caucasian patients with localized prostate cancer. BJU Int 93: 1207-1210, 2004. 